\title{
ACTIVE NOISE ATTENUATION USING LQG/LTR CONTROL
}

\author{
José Paulo F. Garcia, Edson S. Bortoloto, Jean Marcos S. Ribeiro and Lizete Maria C. F. Garcia \\ UNESP - State University of São Paulo \\ Department of Electrical Engineering \\ ZIP - 15385-000 - P.O. Box 31 - Ilha Solteira - SP - Brazil \\ e-mail: jpaulo@dee.feis.unesp.br
}

\begin{abstract}
This paper presents a control system design for active noise cancellation using "Linear Quadratic Gaussian / Loop Transfer Recovery" (LQG/LTR). An implementation by an equipment like a headset is proposed, where both active and passive attenuation techniques are used. In this paper, the active technique is applied to attenuate low-frequency acoustic noise. The design objective is not only the active attenuation of acoustic noise, but also the sound audition at frequency band of the human voice. Results obtained from digital simulations are presented, which is considering the existence of a noise in the environment located near the turbine in a hydroelectric plant. In this noisy environment, the noise is attenuated and the equipment allows the user to hear human voices.
\end{abstract}

Keywords - Active noise control; LQG/LTR control; stability robustness.

\section{INTRODUCTION}

Several devices using both passive and active techniques have been proposed to solve the acoustic noise problem [110]. Circling, blockades and absorbing are classified as passive methods that attenuate or weaken the noise power. They are the most common ways and usually more efficient at high-frequency band; however, for attenuation of lowfrequency noise they are big and expensive [1].

Active noise cancellation is an approach to noise reduction which a secondary noise source that destructively interferes with the unwanted noise is introduced. So, an active noise control (ANC) generates an anti-noise of equal amplitude and opposite phase that, combined with the primary noise, results in the cancellation of the signal [2]. ANC is used in automotive electronic mufflers, passenger compartments, air ducts, air-conditioning ducts, blowers, wind tunnels, public phone booths, office cubicle partitions headsets, airplanes, boats, helicopters, motorcycles, diesel locomotives, and so on [2].

The ANC demanding characteristics have maximum efficiency over large bands, easy installation, stability robustness and self-adaptability to variations in physical conditions.

In this paper is proposed an active headset [3] with LQG/LTR control design, which it is briefly reviewed in the Section II. Section III shows the LQG/LTR design applied on acoustic noise attenuation problem. It is considered that the noise arises from a hydroelectric plant, where low-frequency

Manuscript Received July 27, 2004. Revised October 01, 2004. Revised November 11, 2004. Recommended by Special Editor, Prof. Pedro Francisco Donoso-Garcia. noise is predominant. In section IV, some results obtained from digital simulations are shown.

\section{LQG/LTR CONTROL REVIEW}

"Linear Quadratic Gaussian / Loop Transfer Recovery" (LQG/LTR) is a technique of control design for multivariable systems, whose main features are [11-12]:

- Stability robustness, because of disturbances and uncertainties in the plant;

- $\quad$ Systematized design procedure;

- Frequency approach;

- $\quad$ Reduced number of design parameters.

The feedback representation is illustrated in Figure 1. It consists in the interconnected plant $\left(G_{N}(s)\right)$ and controller $(K(s))$ forced by reference $(r(s))$, measurement noise $(n(s))$, and disturbances $(d(s))$. It is assumed all disturbances are to be reflected in the measured outputs $(y(s))$ and all signals are multivariable, in general.

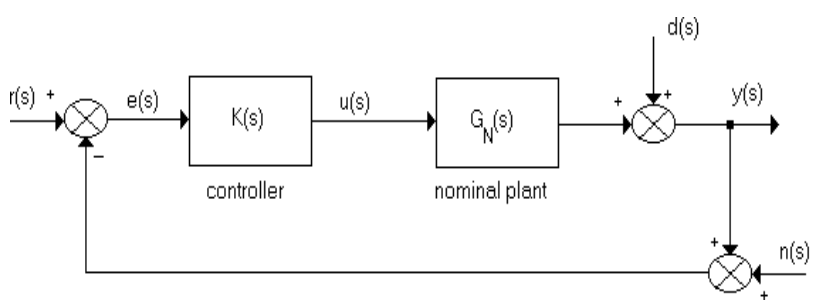

Fig. 1. LQG/LTR feedback representation.

The controller $(K(s))$ must attend the conditions for performance and stability. The objectives to be fulfilled by the real system are:

- Reference signal tracking;

- External perturbation rejection;

- Insensibility to plant variation;

- Measure error rejection.

Concerning the stability, the controller must be such as every class of considered real systems result in stable systems. The design procedure is detailed in [11-12].

\section{LQG/LTR APPLIED ON ACTIVE NOISE ATTENUATION PROBLEM}

\section{A. Problem Establishment}

We supposed that the proposed equipment is used in environments that have low-frequency noises (30 to $120 \mathrm{~Hz})$, for example, region near a turbine in a hydroelectric plant. This situation justifies the use of active attenuation, once the 
passive methods are more efficient on high frequencies, but inefficient to attenuate low-frequency signals.

The LQG/LTR control is efficient when the reference signal (human voice or silence) and the disturbance (acoustic noise) are of low frequency [11-12].

\section{B. Physical Design}

Figure 2 shows a physical representation of the proposed equipment. The headset system is designed to attenuate the acoustic noise around person's ears, and includes a loudspeaker and a microphone placed inside of the headset, connected by a feedback controller. An external microphone also composes the system, which has sensibility on a specific band (for example, the human voice). It is considered the existence of a high-frequency noise originated from microphone, which should not influence the system's performance. The loudspeaker generates an anti-noise capable to reduce the noise and also to transmit the sound that one wants to hear (reference signal).

Taking into account the LQG/LTR approach, we consider that (Figure 1):

$r(s)$ is the reference signal, which could be the sound's pressure due to the human voice (captured by the external microphone), or it could be the silence (external microphone off);

$e(s)$ is the error signal, that is, the sound's pressure inside the capsule (captured by the internal microphone);

$u(s)$ is the electric control signal;

$d(s)$ is the low-frequency acoustic noise, which must be attenuated;

$y(s)$ is the output signal, that is, the sound at user's ear;

$n(s)$ is the measured noise (high-frequency signal) from the internal microphone and it must be eliminated by the system.

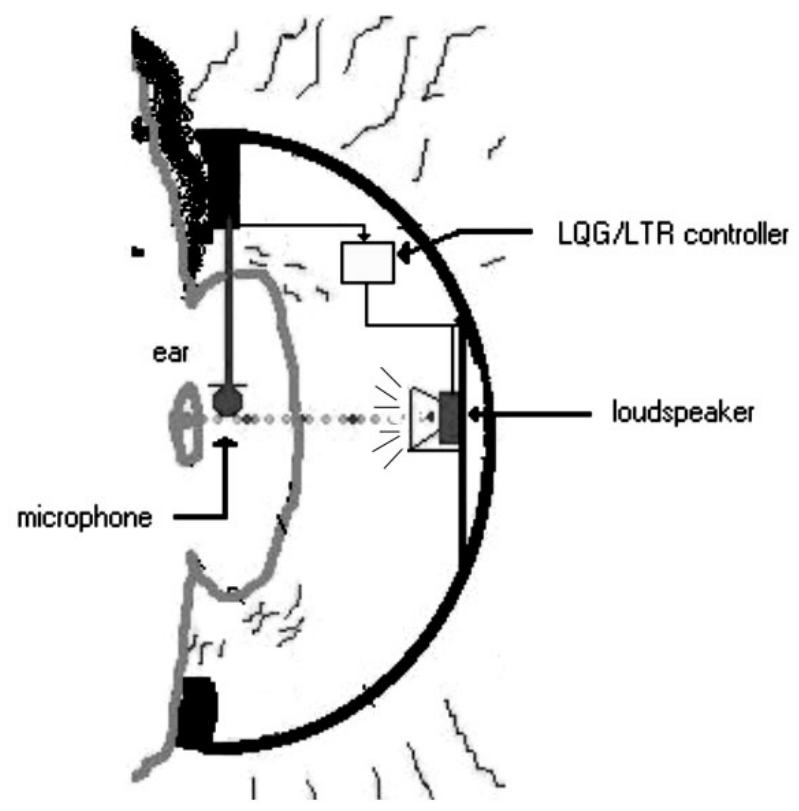

Fig. 2. Physical representation of the proposed system.

\section{Plant Model}

The transfer function used to represent the nominal plant is [13]

$$
G_{N}(s)=\frac{P(s)}{V(s)}=\frac{R_{a c} S_{D} B l}{L m s^{2}+(R m+L r) s+\left[R r+(B l)^{2}\right]}
$$

where

$R_{a c} \quad$ Acoustic resistance (1 N.s/m.r).

$S_{D}=\pi r_{a}^{2} \quad$ Loudspeaker surface area;

$r_{a} \quad$ Loudspeaker ray $(0.018 \mathrm{~m})$;

$B \quad$ Magnetic field $(0.8 \mathrm{~T})$;

$l \quad$ Product of the turn number by average perimeter $(0.75)$;

$L \quad$ Coil inductance $(0.01 \mathrm{H})$;

$m \quad$ Mass of assembly coil/cone $(0.002 \mathrm{Kg})$;

$R \quad$ Electrical resistance of coil $(0.2 \Omega)$;

$r \quad$ Coefficient of stiff friction (0.01);

$P(s) \quad$ Acoustic pressure in the output, and

$V(s) \quad$ Voltage applied on the loudspeaker.

\section{Model Error}

For LQG/LTR robust control design, the real plant $G_{R}(s)$ differs of the nominal plant $G_{N}(s)$, but the number of unstable poles of $G_{R}(s)$ and $G_{N}(s)$ are considered the same. Figure 3 represents the real system. $G_{e r}(s)$ corresponds to uncertainties of the nominal plant.

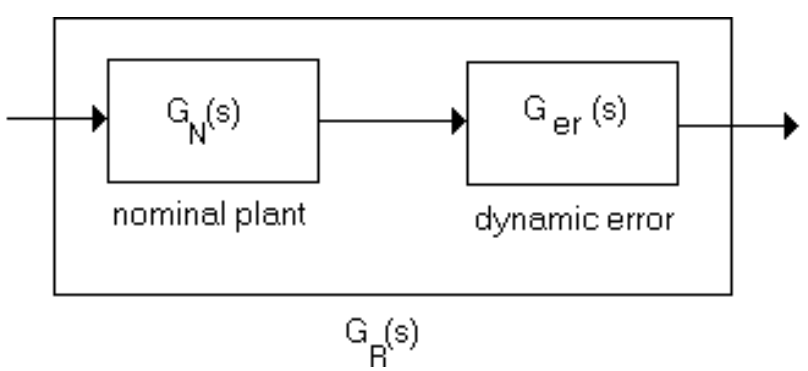

Fig. 3. Real system representation.

We suppose that the dynamic error $G_{e r}(s)$ is effective only at high frequencies, thus we consider that

$$
G_{e r}(s)=\frac{5.10^{7}}{0.1 s^{2}+50 \xi s+5.10^{7}}
$$

where $\xi=0.1$.

Figure 4 shows the gain of the closed-loop transfer function $\left(\left|C_{N}(j \omega)\right|\right)$, with the amplitude of the inverse of the maximum value of the model error $(1 / e(\omega))$. The stability is warranted if [11-12]

$$
\left|C_{N}(j \omega)\right|<\frac{1}{e(\omega)} \leq \frac{1}{|\varepsilon(j \omega)|} \text { for } \forall \omega \in \mathfrak{R},
$$

where

$$
\mathcal{E}_{M}(s)=\left[G_{R}(s)-G_{N}(s)\right] G_{N}^{-1}(s) .
$$




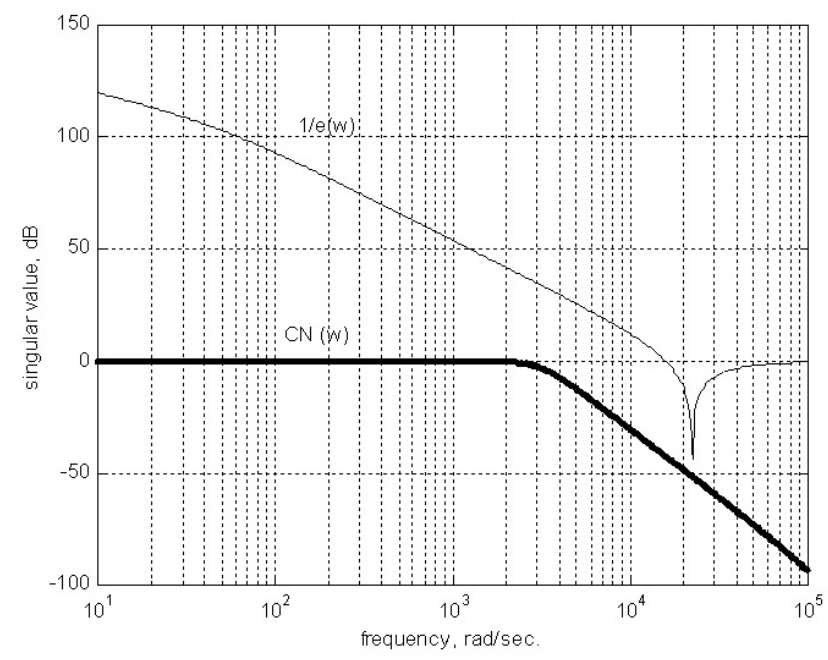

Fig. 4. Frequency response of the closed-loop of the nominal system and frequency response of the model error inverse.

The proposed method is efficient at low-frequency bandwidth, as it can be seen by the analysis of the results to proceed.

\section{OBTAINED RESULTS FROM DIGITAL SIMULATIONS}

Figure 5 shows the system's representation used for digital simulations. In these simulations, the frequency of the acoustic noise is between 30 and $120 \mathrm{~Hz}$ (turbine sound) and it is considered that there is a noise of $20 \mathrm{kHz}$. These simulations were accomplished using the real model (Figure 3 and equation 2). Two situations are considered. In the first case it is considered that the reference signal is the silence, i.e., the only objective of the proposed controller is the noise cancellation. In the second case it is considered that a reference voice exists, and the user wants to hear it, and in this case a low-frequency acoustic noise is also present, which it should be attenuated.

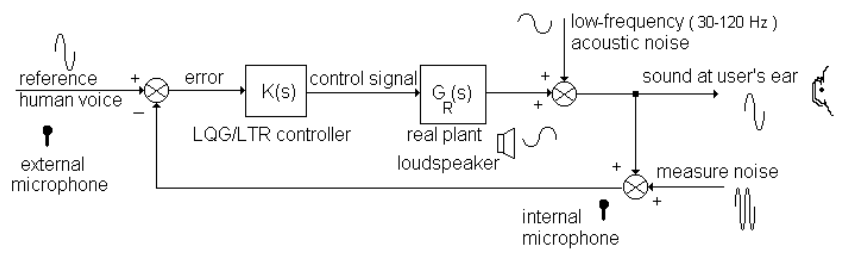

Fig. 5. System used for the digital simulations.

\section{A. Silence as reference}

In these simulations there is no reference signal, i.e., the external microphone is off. In this case the main objective is to eliminate the noise in the user's ears.

The results of the simulations are shown in the Figure 6 . In this case, the noise is quite reduced in the low-frequency range.

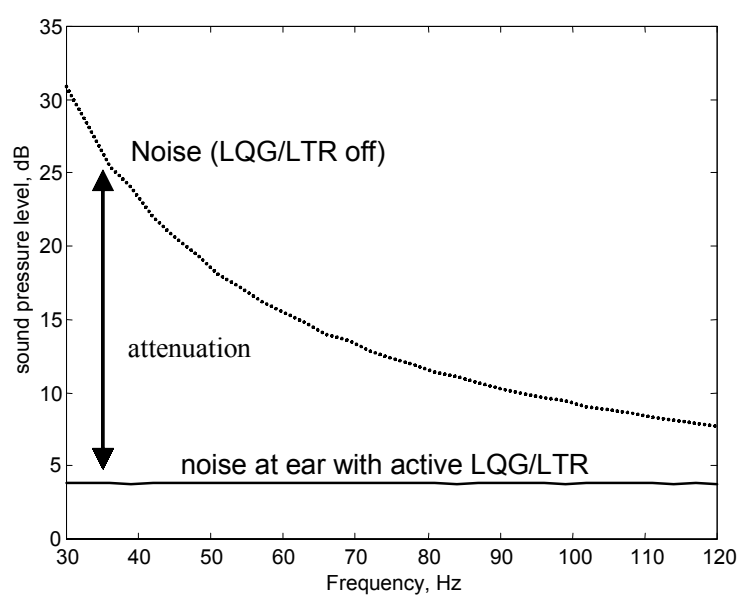

Fig. 6. Obtained results: efficient performance at low frequencies.

\section{B. Human voice as reference}

The objectives of the simulations are the noise elimination and the user being able to listen to a person nearby.

Figure 7 shows the noise, the reference voice signal (captured by the external microphone) and the sound reaching the user's ear with proposed LQG/LTR active control. In this simulation, the frequency of the human voice (reference) is between 100 and $1000 \mathrm{~Hz}$. In this case, the noise influence was quite reduced and the human voice arrives at the user's ear with a little delay, even with measured noise and model error.

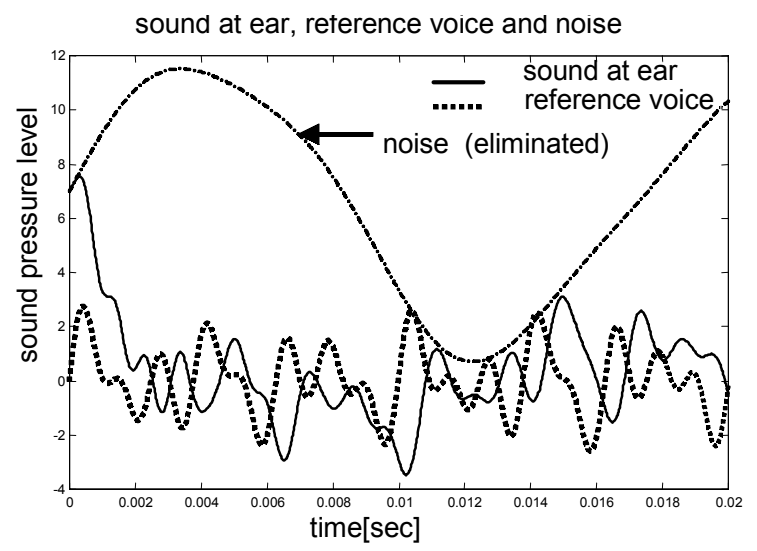

Fig. 7. Time response: noise at 30 to $120 \mathrm{~Hz}$ and reference voice at 100 to $1000 \mathrm{~Hz}$.

In figure 8 is shown the noise, the reference voice signal (captured by the external microphone) and the sound at the user's ear with proposed LQG/LTR active control. In this simulation, the frequency of the human voice (reference) is between 230 and $2000 \mathrm{~Hz}$. In this case, the noise influence was quite reduced but the human voice arrives at the user's ear with distortion. Thus, the proposed controller is only efficient for low-frequency reference signals. 


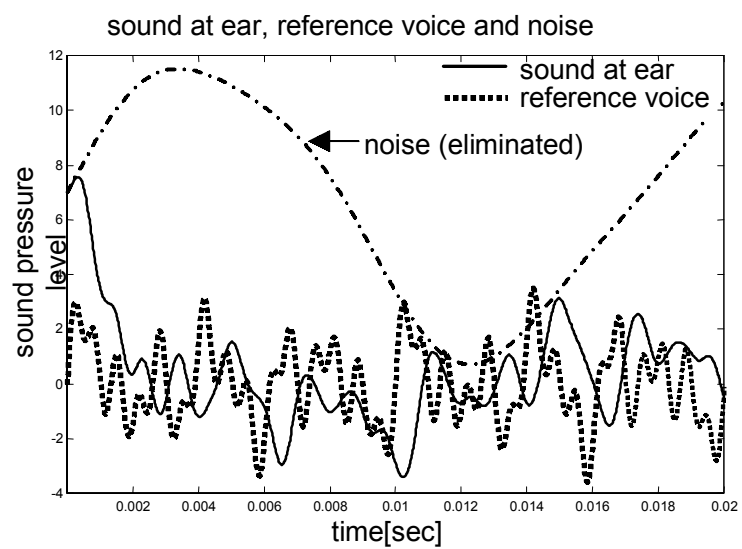

Fig. 8. Time response: noise at 30 to $120 \mathrm{~Hz}$ and reference voice at 230 to $2000 \mathrm{~Hz}$.

Figure 9 shows the measured noise signal at $20 \mathrm{KHz}$ and the sound at the user's ear with proposed LQG/LTR active control. It is noticed that the measured noise influence was eliminated and that the human voice arrives at the user's ear, even with measured noise and model error.

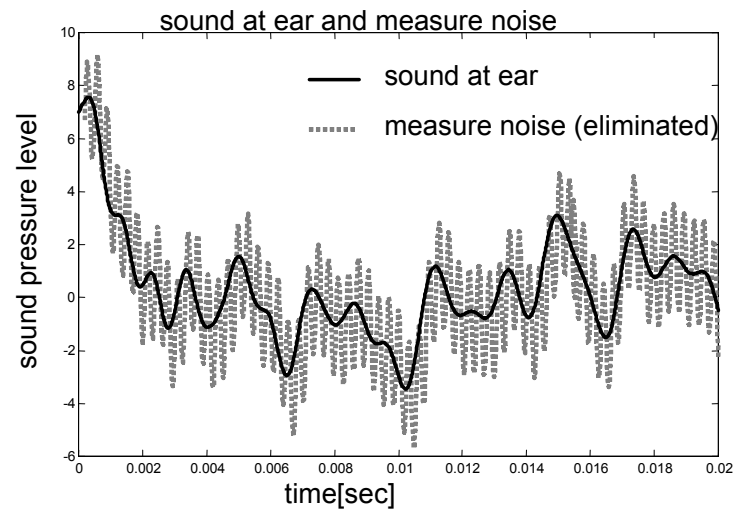

Fig. 9. Measured noise at $20 \mathrm{KHz}$ and sound at the user's ear.

\section{CONCLUSION}

In this paper was considered an environment where noise power is more elevated at low-frequency band, as for example in a region near turbines of a hydroelectric plant. We proposed an active noise control, using LQG/LTR robust control design.

The results obtained by digital simulations confirm the effectiveness of the method when the acoustic noise and the reference signal are of low frequency. In these conditions, the acoustic noise is attenuated and the user is able to hear the person close to him, even if considering the uncertainties in the plant and noise in the measured signal.

\section{ACKNOWLEDGMENTS}

The authors wish to express their gratitude to CNPq, for its financial support in this project.

\section{REFERENCES}

[1] H. Sano, T. Inoue, A. Takahashi, K. Terai, and Y. Nakamura, "Active Control System for LowFrequency Road Noise Combined With an Audio System", IEEE Trans. on Speech and Audio Processing, vol. 9, no. 7, October 2001.

[2] S.M. Kuo and D.R. Morgan, "Active Noise Control: A Tutorial Review", Proc. of the IEEE, vol. 87, no. 6, p. 941-972, June 1999.

[3] S.J. Elliott, "Practical control systems for combatting audible noise show up in aerospace, general aviation, and military roles", IEEE Spectrum, p. 54-61, June 1999.

[4] Chang, C.-Y.; Shyu, K.-K. "Active noise cancellation with a fuzzy adaptive filtered-X algorithm”. Circuits, Devices and Systems, IEE Proceedings, vol. 150, p. 416-422, Oct. 2003.

[5] Jiun-Hung Lin; Kuang-Jung Wu; Ping-Ting Liu; Chu, W.; Shuenn-Tsong Young. "A design for active noise cancellation in the 2 cc coupler". Acoustics, Speech, and Signal Processing, 2002. Proceedings, vol. 4, p. 13-17, May 2002

[6] Cheng-Yuan Chang; Kuo-Kai Shyu. "A self-tuning fuzzy filtered-U algorithm for the application of active noise cancellation". IEEE Transactions on Circuits and Systems I: Fundamental Theory and Applications, vol. 49, p. 1235-1333, Sept. 2002.

[7] Belur, M.N.; Banavar, R.N.; Mahindrakar, A.D. "Active noise cancellation using $\mathrm{H} / \mathrm{sub} / \mathrm{spl}$ infin// control techniques". Proceedings of Industrial Technology, p. 192-195, Jan. 2000.

[8] Yue Wang; Chun Zhang; Zhihua Wang . "A new variable step size LMS algorithm with application to active noise control". Proceedings Acoustics, Speech, and Signal, p. 573-5, April 2003.

[9] Chaoui, J.; de Gregorio, S.; Gallissian, G.; Masse, Y. "DSP-based solution for ambient noise reduction in mobile phones". Proceedings Acoustics, Speech, and Signal Processing, p. 2391-2394, March 1999.

[10]2003 IEEE Workshop on Applications of Signal Processing to Audio and Acoustics Applications of Signal Processing to Audio and Acoustics, 2003 IEEE Workshop on., p. 19-22, Oct. 2003.

[11]J.C. Doyle and G. Stein, "Multivariable Feedback Design: Concepts for a Classical/Modern Synthesis", IEEE Trans. on Automatic Control, vol. AC-26, no. 1, February 1981.

[12] Cruz J.J. “Controle Robusto Multivariável”, Ed. USP, São Paulo, 1996.

[13]A. G. Falcone, Eletromecânica, Ed. Edgard Blücher Ltda., São Paulo, Brasil. 1985 (vol.2).

\section{BIOGRAPHIES}

José Paulo Fernandes Garcia received his B.Sc. degree from the State University of São Paulo (UNESP), Ilha Solteira, Brazil, a M.Sc. degree from the Federal University of Santa Maria (UFSM), Brazil, and Ph.D. degree from de University of São Paulo (USP), São Paulo, Brazil, all in 
Electrical Engineering. He has been with Department of Electrical Engineering/UNESP/Ilha Solteira since 1987, where he has been teaching electrical machines and control systems courses for both graduate and undergraduate students. His research interest includes high performance drives and control theory and application. He is a member of Brazilian Society of Automatic Control.

Edson dos Santos Bortoloto received his B.Sc. and M.Sc. degree from the State University of São Paulo (UNESP), Ilha Solteira, Brazil, in Electrical Engineering. His reserch interest includes active noise control.

Jean Marcos de Souza Ribeiro received his B.Sc. and M.Sc. degree from the State University of São Paulo (UNESP), Ilha Solteira, Brazil, in Electrical Engineering. He has concluding your Ph.D. degree from State University of São Paulo (UNESP), Ilha Solteira, Brazil, in Electrical Engineering. His research interest includes control theory and industry application.

Lizete Maria Crnkowise Fernandes Garcia received his B.Sc. degree from the Federal University of São Carlos (UFsCar), Brazil, in mathematical area, a M.Sc. degree from University of São Paulo (USP), São Carlos, Brazil, in mathematical area and Ph.D. degree from de University of São Paulo (USP), São Paulo, Brazil, in Electrical Engineering. She has been with Department of Mathematics / UNESP/ Ilha Solteira since 1986, where he has been teaching mathematics courses for graduate students. Her research interest is control theory and mathematics theory and application. 